\title{
Comparative Transcriptome Analysis in Homo- and Hetero-Grafted Cucurbit Seedlings
}

\section{OPEN ACCESS}

Edited by:

Francisco Perez-Alfocea, Center for Edaphology and Applied Biology of Segura, Spanish National

Research Council (CS/C), Spain

Reviewed by: Nebahat Sari,

Çukurova University, Turkey Alfonso Albacete, Instituto Murciano de Investigación y Desarrollo Agrario y Alimentario

(IMIDA), Spain

${ }^{*}$ Correspondence: Athanasios Koukounaras thankou@agro.auth.gr

Specialty section: This article was submitted to Crop and Product Physiology,

a section of the journal

Frontiers in Plant Science

Received: 05 April 2021 Accepted: 27 September 2021 Published: 28 October 2021

Citation:

Bantis F, Tsiolas G, Mouchtaropoulou E, Tsompanoglou I, Polidoros AN, Argiriou A and Koukounaras A (2021) Comparative

Transcriptome Analysis in Homoand Hetero-Grafted Cucurbit

Seedlings.

Front. Plant Sci. 12:691069. doi: 10.3389/fp/s.2021.691069

\section{Filippos Bantis ${ }^{1}$, George Tsiolas ${ }^{2}$, Evangelia Mouchtaropoulou ${ }^{2}$, Ioanna Tsompanoglou ${ }^{1}$, Alexios N. Polidoros ${ }^{1}$, Anagnostis Argiriou ${ }^{2,3}$ and Athanasios Koukounaras ${ }^{1 *}$}

'School of Agriculture, Aristotle University of Thessaloniki, Thessaloniki, Greece, ${ }^{2}$ Centre for Research and Technology Hellas, Institute of Applied Biosciences, Thessaloniki, Greece, ${ }^{3}$ Department of Food Science and Nutrition, University of the Aegean, Myrina, Greece

Watermelon (Citrullus lanatus) is a valuable horticultural crop with nutritional benefits grown worldwide. It is almost exclusively cultivated as grafted scions onto interspecific squash rootstock (Cucurbita maxima $\times$ Cucurbita moschata) to improve the growth and yield and to address the problems of soilborne diseases and abiotic stress factors. This study aimed to examine the effect of grafting (homo- and hetero-grafting) on the transcriptome level of the seedlings. Therefore, we compared homo-grafted watermelon (WW) with non-grafted watermelon control (W), homo-grafted squash (SS) with nongrafted squash control (S), hetero-grafted watermelon onto squash (WS) with SS, and WS with WW. Different numbers of differentially expressed genes (DEGs) were identified in each comparison. In total, 318 significant DEGs were detected between the transcriptomes of hetero-grafts and homo-grafts at $16 \mathrm{~h}$ after grafting. Overall, a significantly higher number of downregulated transcripts was detected among the DEGs. Only one gene showing increased expression related to the cytokinin synthesis was common in three out of four comparisons involving WS, SS, and S. The highest number of differentially expressed (DE) transcripts (433) was detected in the comparison between SS and S, followed by the 127 transcripts between WW and W. The study provides a description of the transcriptomic nature of homo- and hetero-grafted early responses, while the results provide a start point for the elucidation of the molecular mechanisms and candidate genes for the functional analyses of hetero-graft and homo-graft systems in Cucurbitaceae and generally in the plants.

Keywords: Citrullus lanatus, scion, rootstock, healing, RNA-seq

\section{INTRODUCTION}

Watermelon [Citrullus lanatus (Thunb.) Matsum. and Nakai] is a plant species cultivated for its highly nutritious fruits which contain about $92 \%$ water and $6 \%$ sugars, and are rich in vitamin C, lycopene, and citrulline (Erhirhie and Ekene, 2013). It is a valuable crop cultivated worldwide with over 100 million tons of annual production (Food and Agriculture Organization of the United Nations, 2012). Nevertheless, watermelon cultivation can be limited because of its sensitivity to soilborne diseases, low and high temperatures, organic pollutants, heavy metals, high salinity, drought, 
and insect pests (Garcia-Lozano et al., 2020). In Western European countries and Greece, vegetable grafting has become of interest in the last decade, especially due to the ban of methyl bromide as a soil disinfectant in 2005 and the high demand for environmentally friendly products (Davis et al., 2008). Grafting is the main propagation technique in many leading countries for watermelon production, such as South Korea, Japan, Spain, Italy, and Greece. In 2005, over $90 \%$ of the grafted watermelon seedlings were used in Japan and Korea and the production exceeded 300 million grafted seedlings. In 2009, Spain and Italy jointly produced 60 million grafted watermelon seedlings (Lee et al., 2010), while in Greece about 19 million grafted watermelon seedlings are produced annually (Bantis et al., 2019). High compatibility can be achieved between the watermelon scions and watermelon rootstocks (Fallik et al., 2019) or interspecific squash hybrid rootstocks, such as TZ-148 (Cucurbita moschata $\times$ C. maxima) which is the most common rootstock for the grafted watermelon seedlings throughout the world (Lee et al., 2010).

Vegetable grafting is a propagation technique that offers several benefits during crop production. The technique involves two segments, the scion and the rootstock, which conjoin and form a grafted seedling with desired features. Briefly, grafting increases the plant resistance against biotic (i.e., soil-borne pathogens) (Lee et al., 2010; Louws et al., 2010) and abiotic (i.e., heavy metals, salinity, and low temperatures) (Savvas et al., 2010; Schwarz et al., 2010) stress factors, improves the fruit quality and ripening behavior (Soteriou et al., 2014), and enhances plant vigor due to the higher rootstock activity (Savvas et al., 2010). Grafting is characterized as "homo-grafting" when the scion and rootstock are seedlings from the same species, or as "hetero-grafting" when the scion and rootstock are seedlings from different species (Yeoman and Brown, 1976). Biological molecules, such as nutrients, hormones, proteins, and genetic material are transported through graft fusion due to the interaction between the two graft segments. Several types of research have been conducted, revealing the molecular responses at the grafting site and there is significant evidence that the movement of genetic material (organelle and nuclear DNA) at the grafting site and the grafting induced changes are stably inherited in the subsequent generations (Taller et al., 1999; Stegemann and Bock, 2009; Stegemann et al., 2012; Tsaballa et al., 2013; Fuentes et al., 2014). Stegemann and Bock (2009) were the first who proposed that grafting provides a path for horizontal gene transfer (HGT), based on their experimental studies in which after grafting of genetically modified tobacco plants, plastid genes were able to travel over the grafting point, noting that the gene transfer is confined to the graft site and no long-distance transfer may occur and "graft hybridization" would not be analogous to the sexual hybridization. On the contrary, Fuentes et al. (2014) detected nuclear genome transfer between the scion and rootstock resulting in new fertile and stable allopolyploid species, thus proposing that grafting should be used as an alternative way of polyploidization, while interspecies grafting could allow a method to produce new allopolyploid crop species, offering a remarkable potential in breeding (Fuentes et al., 2014). Beyond the DNA movement across the graft union, there is numerous research associated with epigenetic modification in the grafted plants regulated by the transmittable small RNA, miRNA, mRNA, and proteins (Sharma and Zheng, 2019).

The process of successful grafting depends on wound healing, following this order: wound response, cell regeneration, cell proliferation, cell-cell adhesion, and cell differentiation (Goldschmidt, 2014; Gaut et al., 2019). The plants use the vascular tissue (xylem and phloem) to transport water, nutrients, photosynthetic products, and signaling molecules, such as plant hormones, and to provide mechanical support (Nanda and Melnyk, 2018). The vascular adhesion process has been wellstudied, but the molecular mechanisms underlying this process remain not fully understood. It has been established, however, that the plant hormones, such as auxins, cytokinins (CKs), ethylene (ET), gibberellins (GAs), and jasmonic acid (JA) play a crucial role in the regulation of physiological processes taking place at the graft junction (Melnyk et al., 2015; Ikeuchi et al., 2017; Nanda and Melnyk, 2018). Specifically, the plant hormones are the signaling molecules, responding to either artificial or natural plant wounds. Regarding the wound response promoted by CK and by the WOUND INDUCED DEDIFFERENTIATION 1 (WIND1) pathway, which is upregulated upon wounding, and the overexpression of this gene results in excess callus formation (Iwase et al., 2011). A plethora of research has proved the vital role of auxin in the process of graft union (Sharma and Zheng, 2019), and the results from the work of Melnyk et al. (2015) enhance the significance of auxin in vascular formation, such as a new role for ALF4.

To determine the gene expression and related transcriptional networks and the metabolic activities pertinent to successful grafting, we examined the transcription in different grafting combinations between the interspecific squash rootstock and watermelon scion. In this study, we used controls of the nongrafted seedlings and homo-grafted squash and watermelon to examine the alteration of gene expression in watermelonsquash hetero-grafts. The transcriptomic data were analyzed using bioinformatic tools to detect the differentially expressed genes (DEGs) during the early stages of the healing process. A significant hormone regulating gene (LOG5) detected in the grafting combinations involving squash as rootstock was further validated using a quantitative real-time PCR (qPCR) analysis. This study provides a description of potential groundwork for the elucidation of critical steps in the healing process of the commercially important watermelon scion and interspecific squash rootstock grafting combinations.

\section{MATERIALS AND METHODS}

\section{Plant Material and Growth Conditions}

The experiment was conducted in Kleidi, Imathia, Greece, in the facilities of Agris S.A. ${ }^{1}$ A transcriptome analysis was performed at the Institute of Applied Biosciences of the Centre for Research and Technology Hellas, Thessaloniki, Greece.

\footnotetext{
${ }^{1}$ http://www.agrishorticulture.com
} 
The grafted seedlings were composed of watermelon [C. lanatus (Thumb.) Matsum. and Nakai] "Celine F1" (regularly used as scions) and interspecific squash (Cucurbita maxima $\times$ Cucurbita moschata, hereafter referred to as squash) "TZ-148" (regularly used as rootstocks) combinations. The watermelon and squash seeds (HM.Clause SA, Portes-LesValence, France) were sown in 171-cell plug trays and 128-cell plug trays $(67 \mathrm{~cm} \times 33 \mathrm{~cm}$, G.K. Rizakos S.A., Lamia, Greece), respectively. The trays were filled with peat, perlite, and vermiculite $(5: 1: 2)$.

Upon sowing, the trays remained in a chamber with controlled conditions (temperature $25^{\circ} \mathrm{C}$, relative humidity $95-98 \%$, and darkness) for $72 \mathrm{~h}$ (watermelon) or $48 \mathrm{~h}$ (squash) to assist germination. After germination, the watermelon trays were moved for 10 days in a greenhouse with $21.5^{\circ} \mathrm{C}$ minimum night temperature and supplemental artificial lighting emitted by the high-pressure sodium lamps (MASTER GreenPower $600 \mathrm{~W}$ 400 V E40, Philips Lighting, Eindhoven, The Netherlands) at photosynthetic photon flux density (PPFD) of $100 \pm 10 \mu \mathrm{mol}$ $\mathrm{m}^{-2} \mathrm{~s}^{-1}$ and $18 \mathrm{~h}$ photoperiod. In parallel, the squash trays were moved in a greenhouse under $20^{\circ} \mathrm{C}$ minimum night temperature for 7 days, and afterward $14^{\circ} \mathrm{C}$ for 3 days to reduce the growth rate and increase the stem thickness. According to the previous experiments of our group, no supplemental artificial lighting was needed for the production of squash seedlings.

\section{Grafting Combinations}

The "splice grafting" technique was employed when the watermelon and squash had developed one true leaf. Table 1 depicts the plant material used in this study. Briefly, the material included non-grafted controls: watermelon (W) and squash (S), homo-grafted watermelon scion grafted onto watermelon rootstock (WW), and squash scion grafted onto squash rootstock (SS); and the hetero-grafted watermelon scion grafted onto squash rootstock (WS). The segments of the grafted seedlings were held together with a silicon clip and planted in 72-cell plug trays $(50 \mathrm{~cm} \times 30 \mathrm{~cm})$ filled with peat, perlite, and vermiculite (3:1:1). Grafting was performed by an experienced person for the avoidance of critical errors. Immediately after grafting, the seedlings from all the combinations were moved in a healing chamber under $25^{\circ} \mathrm{C}$ temperature, $98 \%$ relative humidity, recirculating air, and sole artificial lighting emitted by the fluorescent lamps (Fluora $58 \mathrm{~W}$, Osram, GmbH, Munich, Germany) at PPFD of $45 \pm 5 \mu \mathrm{mol} \mathrm{m} \mathrm{m}^{-2} \mathrm{~s}^{-1}$ and $16 \mathrm{~h}$ photoperiod.

TABLE 1 | Watermelon and interspecific squash grafting combinations tested after $16 \mathrm{~h}$ in a healing chamber.

\begin{tabular}{lcccc}
\hline Abbreviation & Scion & & Rootstock & Grafting combination \\
\hline W & Watermelon & & - & Non-grafted \\
S & Int. squash & & - & Non-grafted \\
WS & Watermelon & $\times$ & Int. squash & Hetero-grafted \\
WW & Watermelon & $\times$ & Watermelon & Homo-grafted \\
SS & Int. squash & $\times$ & Int. squash & Homo-grafted
\end{tabular}

\section{Sampling}

The sampling was conducted after $8 \mathrm{~h}$ of light and $8 \mathrm{~h}$ of darkness (in total $16 \mathrm{~h}$ ) in the healing chamber in almost complete darkness. Specifically, the segments from 15 seedlings per combination were cross-cut with the sterilized blades $0.5 \mathrm{~cm}$ above and below the grafting junction. The segments from the non-grafted seedlings were cut precisely below the cotyledons. After cutting, each segment from all the combinations was immediately wrapped with aluminum foil, submersed into liquid nitrogen, and placed in deep freezing temperature $\left(-80^{\circ} \mathrm{C}\right)$ until molecular analysis.

In the previous (unpublished) experiments of our group, such as microscopy and phytohormonal analysis on the third day after grafting, we concluded that vascular reconnection starts earlier than the third day after grafting. Since phytohormonal activity begins earlier than the third day, molecular activity, such as gene expression and signaling initiates earlier. Moreover, in the first few hours after grafting, the wounding effect takes place, thus we opted to avoid the sampling until $8 \mathrm{~h}$ after grafting. Therefore, we selected the 16-h time point which lies between $8 \mathrm{~h}$ and 3 days after grafting to avoid the wounding effect and not miss the gene expression during the first crucial day.

\section{RNA Isolation, Library Preparation, and Sequencing}

Total RNA was extracted from the grafting junctions with NucleoSpin RNA Plant, Mini kit for RNA from the plant (Macherey-Nagel GmbH \& Co. KG, Germany) from the three biological replicates of each treatment according to the instructions from the manufacturer. The total yield was quantified by a fluorometric method with Qubit ${ }^{\text {TM }}$ RNA BR Assay kit (Cat. No. Q10211, Thermo Fischer Scientific, MA, United States), and the integrity of the isolated genetic material was accessed with agarose gel electrophoresis. For the library construction, the mRNA was purified with oligo-dT ${ }^{(25)}$ magnetic beads (Cat. No. S1419S, New England Biolabs, MA, United States). The libraries were prepared with the NEBNext ${ }^{\circledR}$ Ultra $^{\text {TM }}$ II RNA Library Prep Kit for Illumina ${ }^{\circledR}$ (Cat. No. E7770S, New England Biolabs) according to the instructions from the manufacturer, with an average insert size of 300 base pair (bp). The size of libraries was estimated by capillary electrophoresis with the 5400 Fragment Analyzer system (Agilent, CA, United States) and the final quantification performed by qPCR using the KAPA Library Quantification kit for Illumina ${ }^{\circledR}$ sequencing platforms (Cat. No. KK4824, Roche, Switzerland) on a Rotor-Gene Q thermocycler (Qiagen, Germany). The libraries were sequenced with Illumina ${ }^{\circledR}$ Nexteq500 ${ }^{\circledR}$ platform using the NextSeq ${ }^{\circledR} 500 / 550$ v2.5 High Output Kit (300 cycles) (Cat. No. 20024908, Illumina, CA, United States).

\section{Bioinformatic Analysis}

The differential expression analysis was performed according to the "New Tuxedo" pipeline (Kim et al., 2016). The raw reads filtered with Trim Galore! ${ }^{2}$ for quality (q 28), length (minlength 100), and the sequencing adaptors. The filtered reads of

\footnotetext{
${ }^{2}$ https://www.bioinformatics.babraham.ac.uk/projects/trim_galore/
} 
the samples SS and S were aligned to the C. maxima genome (GCA_002738345.1) and then of the samples WW and W to the C. lanatus genome (GCA_004801215.2) using Hisat $2 .{ }^{3}$ Stringtie $^{4}$ was used for the assembly and quantification of transcripts. Differential expression analysis was performed with Ballgown ${ }^{5}$ in $\mathrm{R}$ studio. In parallel, a de novo transcriptome of the total reads acquired from the different samples was assembled with Trinity $^{6}$ to be used as a reference for the mapping of the reads of different organisms. The assembly completeness was evaluated with $\mathrm{BUSCO}^{7}$ (Figure 1). A genome-like reference file was created with Supetranscripts, a module of Trinity assembler, which was used for the downstream analysis following the same protocol described above. The de novo transcriptome was annotated with Diamond. ${ }^{8}$ The analysis pipeline is depicted in Figure 2. The raw Illumina reads are available under the Bioproject PRJNA721571. ${ }^{9}$

\section{Quantitative Real-Time PCR Analysis}

The total RNA from the segments of homo-grafted WW, SS, hetero-grafted WS, and non-grafted $\mathrm{W}$ and $\mathrm{S}$, which have been harvested at 0 (control), 16, and $24 \mathrm{~h}$ after grafting in the growth chamber with the three biological replicates was extracted using a total RNA isolation kit (Monarch ${ }^{\circledR}$ Total RNA Miniprep Kit, NEB) following the instructions from the manufacturer. All the samples were treated by DNase I for enzymatic removal of residual gDNA. To determine the RNA quality and concentration, $5 \mu \mathrm{l}$ of each RNA sample was analyzed by agarose gel electrophoresis (1.4\%, agarose, $1 \times \mathrm{TBE})$ and quantified using a NanoPhotometer IMPLEN Version 7122 V2.3. The reverse transcription and PCR reactions were performed using a Luna ${ }^{\circledR}$ Universal One-Step reverse transcription-quantitative PCR (RT-qPCR) Kit (E3005) following the instructions from the

${ }^{3}$ http://daehwankimlab.github.io/hisat2/

${ }^{4}$ https://ccb.jhu.edu/software/stringtie/

${ }^{5}$ https://github.com/alyssafrazee/ballgown

${ }^{6}$ https://github.com/trinityrnaseq/trinityrnaseq/wiki

${ }^{7}$ https://busco.ezlab.org/

${ }^{8}$ https://github.com/bbuchfink/diamond

${ }^{9}$ https://www.ncbi.nlm.nih.gov/Traces/study/?acc=PRJNA721571

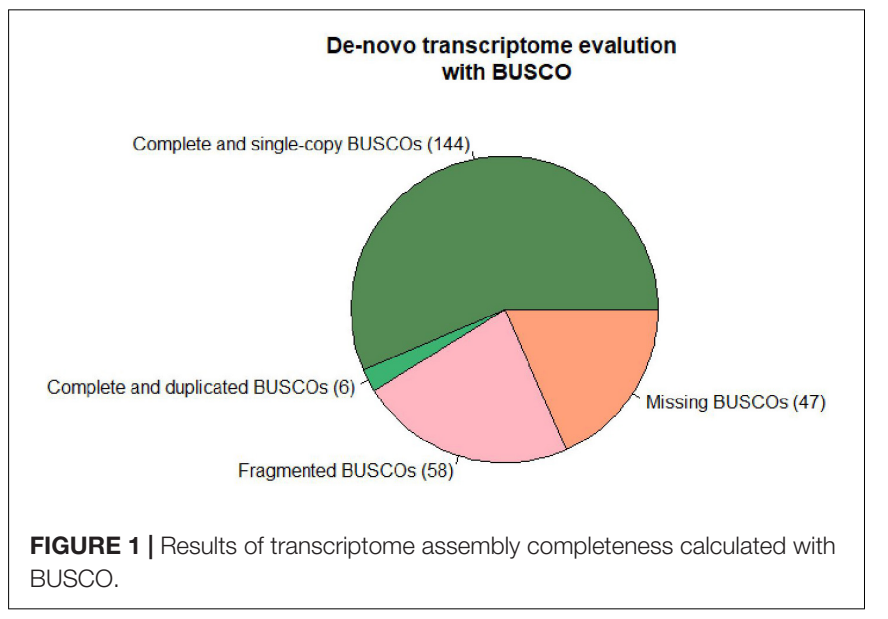

manufacturer with the following steps: total volume for each reaction was $20 \mu \mathrm{l}$, including $10 \mu \mathrm{l}$ Luna Universal One-Step Reaction Mix $(2 \times), 1 \mu$ l Luna WarmStart ${ }^{\circledR}$ RT Enzyme Mix $(20 \times), 0.8 \mu \mathrm{l}$ forward and reverse primers of LOG5, while $0.2 \mu \mathrm{l}$ forward and reverse primers for actin, $20 \mathrm{ng}$ of RNA and nuclease-free water up to $20 \mu \mathrm{l}$. The Roche LightCycler ${ }^{\circledR} 96$ System was used with the following thermal cycling conditions: stage 1 for $\mathrm{RT}, 1$ cycle at $55^{\circ} \mathrm{C}$ for $10 \mathrm{~min}$; stage 2,1 cycle at $95^{\circ} \mathrm{C}$ for $1 \mathrm{~min}$; stage 3,40 cycles at $95^{\circ} \mathrm{C}$ for $10 \mathrm{~s}$ and $60^{\circ} \mathrm{C}$ for $30 \mathrm{~s}$. After amplification, a melting curve analysis was performed to verify the product. At least three biological replicates were performed. The measured $\mathrm{Ct}$ values were converted to relative copy numbers using the $\Delta \Delta \mathrm{Ct}$ method. The primer pairs were for $\log 5$ forward 5'CATCCACGACAAACCAGTTG3' and reverse 5'AGGCACGTACTCCTCTAGTTTCTG3' amplifying a $172 \mathrm{bp}$ product and for actin forward 5'CCATGTATGTTGCCATCCAG3' and reverse 5'GGATAGCATGGGGTAGAGCA3' amplifying a 140 bp product. The primers for the reference gene CIACT (gene ID Cla007792) were based on the published data (Kong et al., 2014), and the primers for LOG5 (gene ID LOC111776908) were designed to amplify a specific sequence region common in the watermelon and squash (based on the published consensus sequences in the Cucurbit Genome Database). ${ }^{10}$ The results were analyzed using the Roche LightCycler ${ }^{\circledR} 96$ software program, version 1.1.

\section{RESULTS}

\section{RNA-Seq Data Analysis}

In total 510 million sequence reads were obtained, corresponding to approximately 17 million raw reads for each sample. After quality filtering, about 42 million of them were excluded from the following analysis due to low quality. The filtered reads of the samples SS and S were aligned to the C. maxima genome and those of the samples WW and W to the C. lanatus genome as described in the section "Materials and Methods." The overall alignment rate was ranging from 69 to $97 \%$ and the total number of genes identified was 29,374 for the grafted squash samples and 21,775 for the watermelon samples (Table 2).

\section{Differentially Expressed Genes}

To assess the effect of grafting in homo-grafted squash and watermelon, differential expression analysis was performed. Among the homo-grafted squash (SS), the biological replicates and the non-grafted plants (S) that were used as controls (comparison SS/S), 238 genes, and 433 transcripts were found to be differentially expressed (DE). Similarly, among the homografted watermelon replicates (WW) and their control (W) replicates (comparison WW/W), 31 genes and 127 transcripts were found to be DE. The comparison among the grafted plants, homo- and hetero-grafted, and their controls (comparison $\mathrm{WS}+\mathrm{SS}+\mathrm{WW} / \mathrm{W}+\mathrm{S}$ ) revealed 318 DEGs (Table 2). A Venn diagram depicting the number of DEGs among the

${ }^{10}$ http://cucurbitgenomics.org/ 


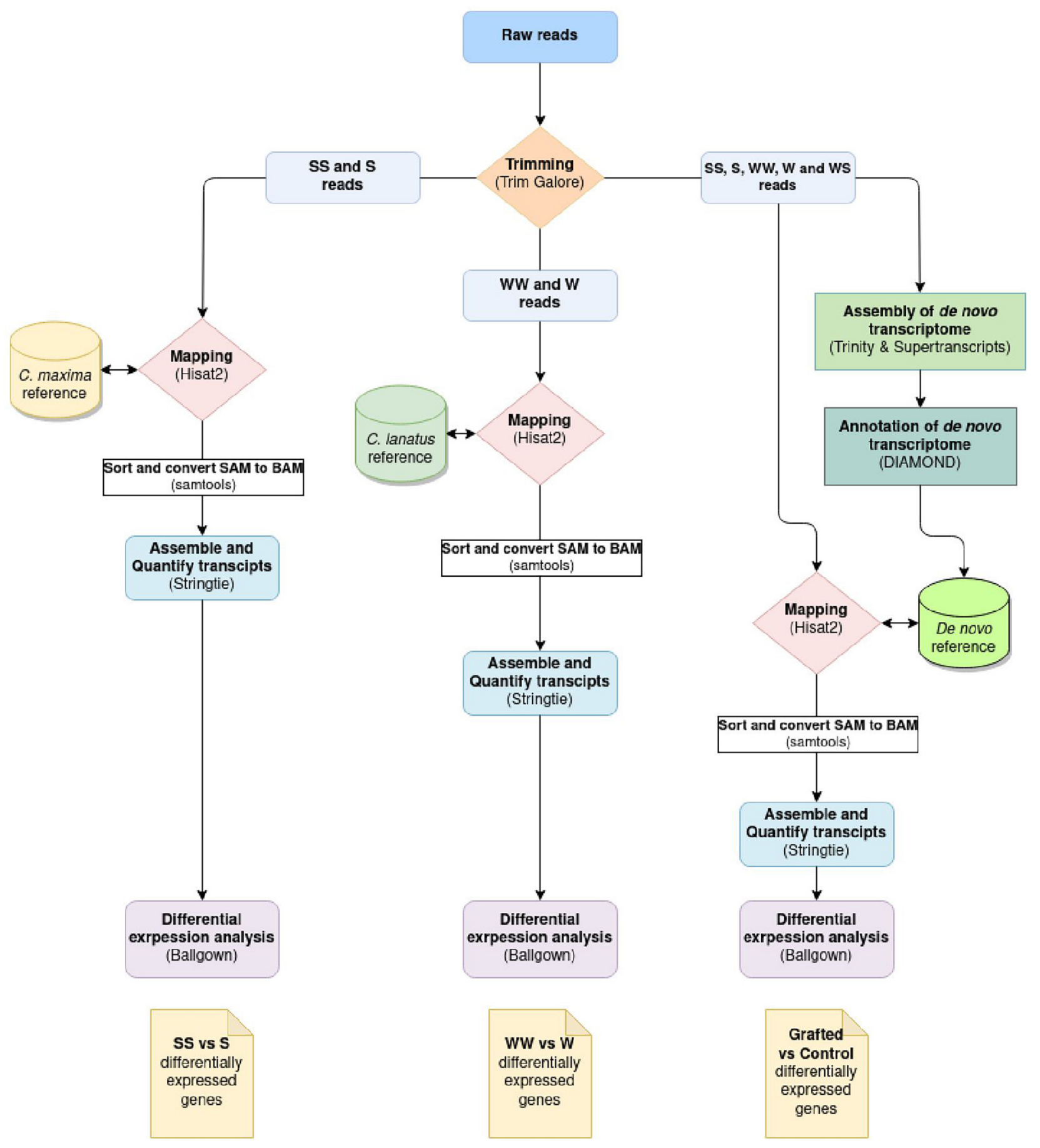

FIGURE 2 | Differential expression analysis workflow. The same workflow was followed for all the three comparisons, which differ only at the reference used for the mapping of the reads.

three comparisons is shown in Figure 3. The detection of DE transcripts was not feasible since, due to the adopted methodology, a de novo transcriptome, was built and used as a reference. This transcriptome consists of transcripts that are highly conserved among the two species and unique transcripts that are expressed only in one of the two species. Although the de novo transcriptome method offers a way to investigate the genes that were affected at the hetero-grafted plants during the process of healing, we cannot be confident about their levels of expression. The two additional comparisons were performed for the hetero-grafted plants (WS) against the two homografted (WW and SS). The comparison WS/WW identified 36 
TABLE 2 | Discovered genes and transcripts with "New Tuxedo" protocols of the three comparisons.

\begin{tabular}{lccc}
\hline & $\begin{array}{c}\text { C. maxima } \\
\text { reference }\end{array}$ & $\begin{array}{c}\text { C. lanatus } \\
\text { reference }\end{array}$ & $\begin{array}{c}\text { De novo } \\
\text { transcriptome }\end{array}$ \\
\hline Total genes & 29,374 & 21,775 & 192,133 \\
Total transcripts & 59,924 & 41,119 & - \\
DE genes & 238 & 31 & 318 \\
DE transcripts & 433 & 127 & -
\end{tabular}

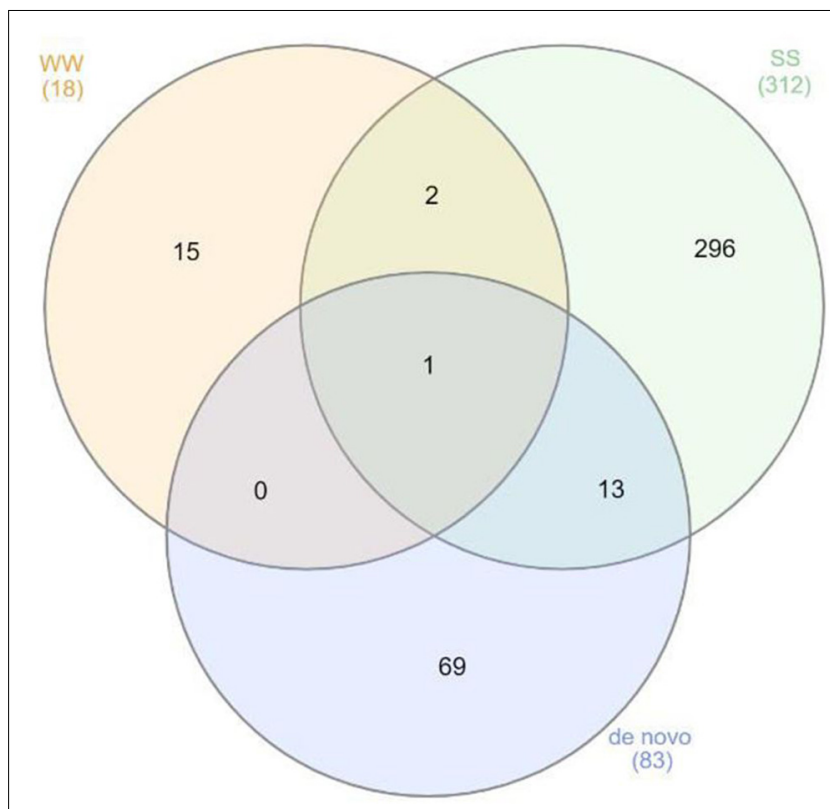

FIGURE 3 | Venn diagram depicting the gene ontologies found to be differentially expressed (DE) among the three comparisons.

and the comparison WS/SS identified $214 \mathrm{DE}$ transcripts. The multidimensional scaling (MDS) plots for grafted plants (WW, SS, and WS) vs. non-grafted controls (W and S) in Figure 4 and a heatmap of DEGs in Figure 5 support this finding. The expression levels of WS samples do not show the fluctuation that is found in WW and SS samples, which is caused by the bioinformatic analysis method where the de novo transcriptome was used as reference.

\section{Functional Analysis of Differentially Expressed Genes}

The assessment of the possible functions of the DEGs was feasible only for the homo-graft comparisons. The analysis revealed that the most common DEGs among WW, SS, and their controls are related to the specific biological processes, mainly associated with the stress responses (Table 3). Similarly, DEGs were found to be commonly over- and under-expressed among the three comparisons of homo- and hetero-grafted plants vs. their control seedlings. Again, the most commonly overexpressed genes (Table 4) are related to known biological mechanisms involved in the stress response.

\section{Validation of LOG5 Expression by RT-qPCR Analysis}

To validate the RNA-Seq expression data for LOG5 that showed relatively high abundance in three out of the four comparisons, we performed RT-qPCR analysis. Total RNA from the stem of seedlings and the graft region including tissue from the rootstock and the scion of homo- and hetero-graft combinations was used as the templates. The RT-qPCR results were consistent with an upregulation of LOG5 found in the RNA-seq analysis. Relative LOG5 expression was stable in the stem of watermelon seedlings after transfer to the growth chamber while showed a decrease in squash (Figure 6). An increase of LOG5 transcript level was detected at $16 \mathrm{~h}$ in all the grafting combinations, which was higher in homo-grafted SS followed by the hetero-grafted WS and homo-grafted WW. Later, at $24 \mathrm{~h}$, the increase was at a lower level in WS and SS while in WW LOG5, the expression was similar to the non-grafted control.

\section{DISCUSSION}

Watermelon is considered an economically important crop, especially in eastern Asia and the Mediterranean region. As soilborne pathogens are virtually impossible to control, grafting has already provided an efficient, among the other benefits, solution for the successful watermelon establishment and cultivation in the field (Kyriacou and Soteriou, 2015). The unpublished observations of our group clearly showed that the process of healing for the grafted watermelon seedlings is characterized by rapid vascular reconnection only 3 days after grafting which is significantly faster than tomato (c.f. Wang et al., 2019) in which the scion and rootstock reconnection was observed after 9 days (Cui et al., 2021). Upon its formation, callus rapidly differentiates in the vascular tissues (i.e., phloem and xylem), while plasmodesmata, the intracellular channels, form between the scion and rootstock cells.

During the healing and tissue reconnection in grafted plants, there are critical molecular events characterized by differential gene expression. These events include the activation of wounding stress responses, such as biosynthesis of the stress-related phytohormones jasmonic acid and ethylene (Yin et al., 2012), and increased expression of ROS scavenging enzymes. The early responses also elicit auxin and brassinosteroid biosynthesis and sugar transport above the cut, increased stress response gene expression below the cut (Xie et al., 2019), and the activation of auxin and $\mathrm{CK}$ responses in the vascular cambium and pericycle (Melnyk et al., 2015). Accordingly, our data show differential regulation of genes involved in the wound and stress responses, hormonal signaling, and metabolite transport.

The stress responses are among the major biological processes identified by the DEGs among the homo-grafted WW and SS plants and their respective non-grafted controls. Mutually DEGs of WW and SS are involved in the response to stress (GO:0006950), response to oxidative stress (GO: 0006979), hydrogen peroxide catabolic process (GO:0042744), with molecular functions, such as oxidoreductase activity (GO:0016491) and peroxidase activity (GO:0004601). Similarly, 


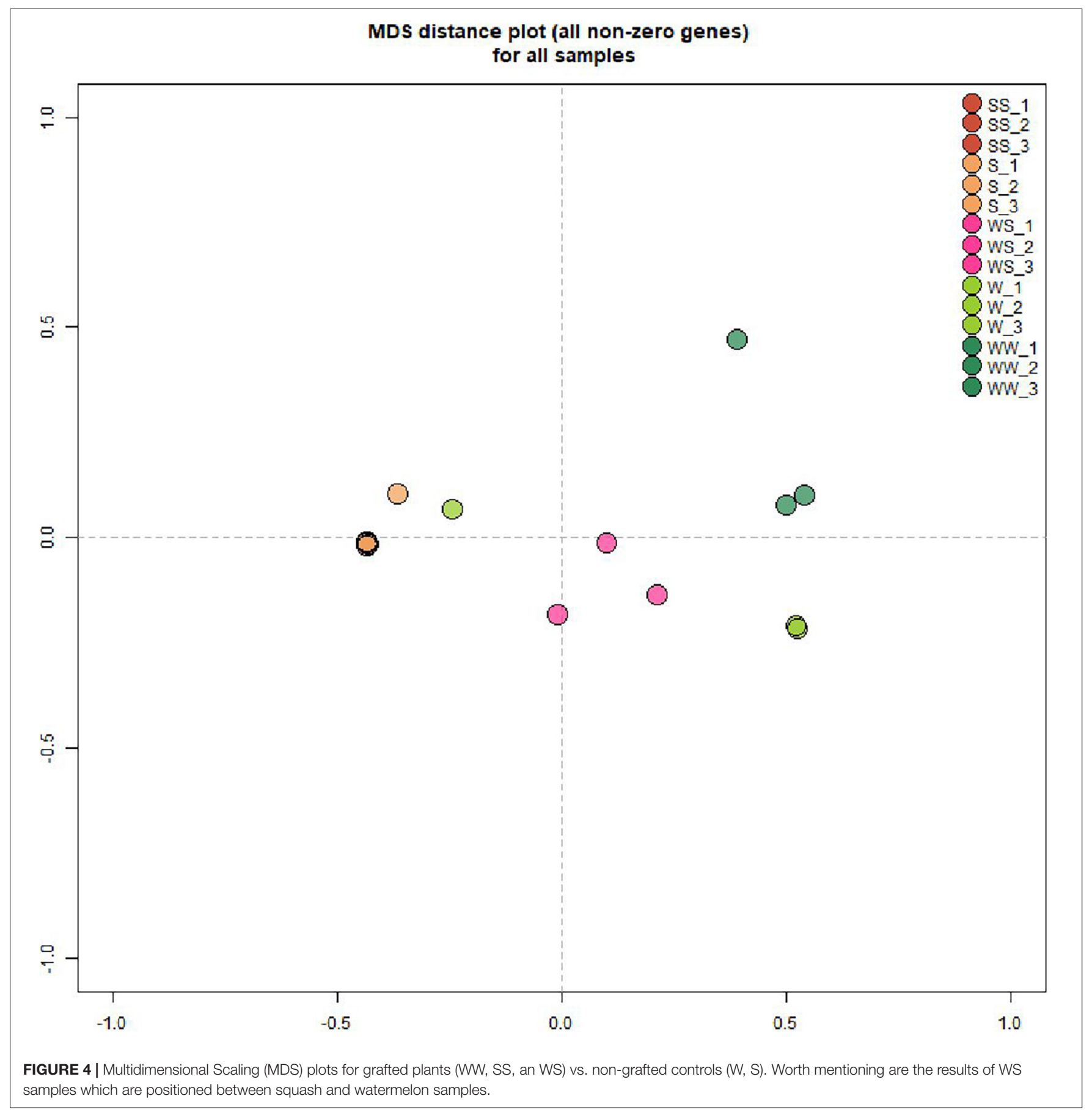

in tomato genes involved in response to the oxidative stress (GO: 0006979), hydrogen peroxide catabolic process (GO: 0042744), and cellular oxidative detoxification (GO: 0098869) were enriched in the grafted plants (Xie et al., 2019). Additionally, in tomatoes, the oxidative detoxification enzymes accumulate to high levels near the graft region (Fernandez-Garcia et al., 2004) indicating that the differential gene expression is linked to function. The plant peroxidases are involved in the important developmental stages, such as lignification, auxin metabolism, reactive oxygen species (ROS) metabolism, and cell wall metabolism (Pandey et al., 2017). Fernandez-Garcia et al. (2004) reported that the peroxidases might be involved in the development of graft union in tomato plants. Similarly, in our study, the peroxidases were found to be over-expressed in all the graft combinations (WW, SS, and WS) compared with the non-grafted watermelon seedlings. Ascorbic acid (AsA) is the most abundant water-soluble antioxidant in the plants, with a significant role in the detoxification of ROS and regulating the cellular redox potential (Mittler, 2002; Suza et al., 2010; Fotopoulos and Kanellis, 2013). AsA is a critical cofactor of 


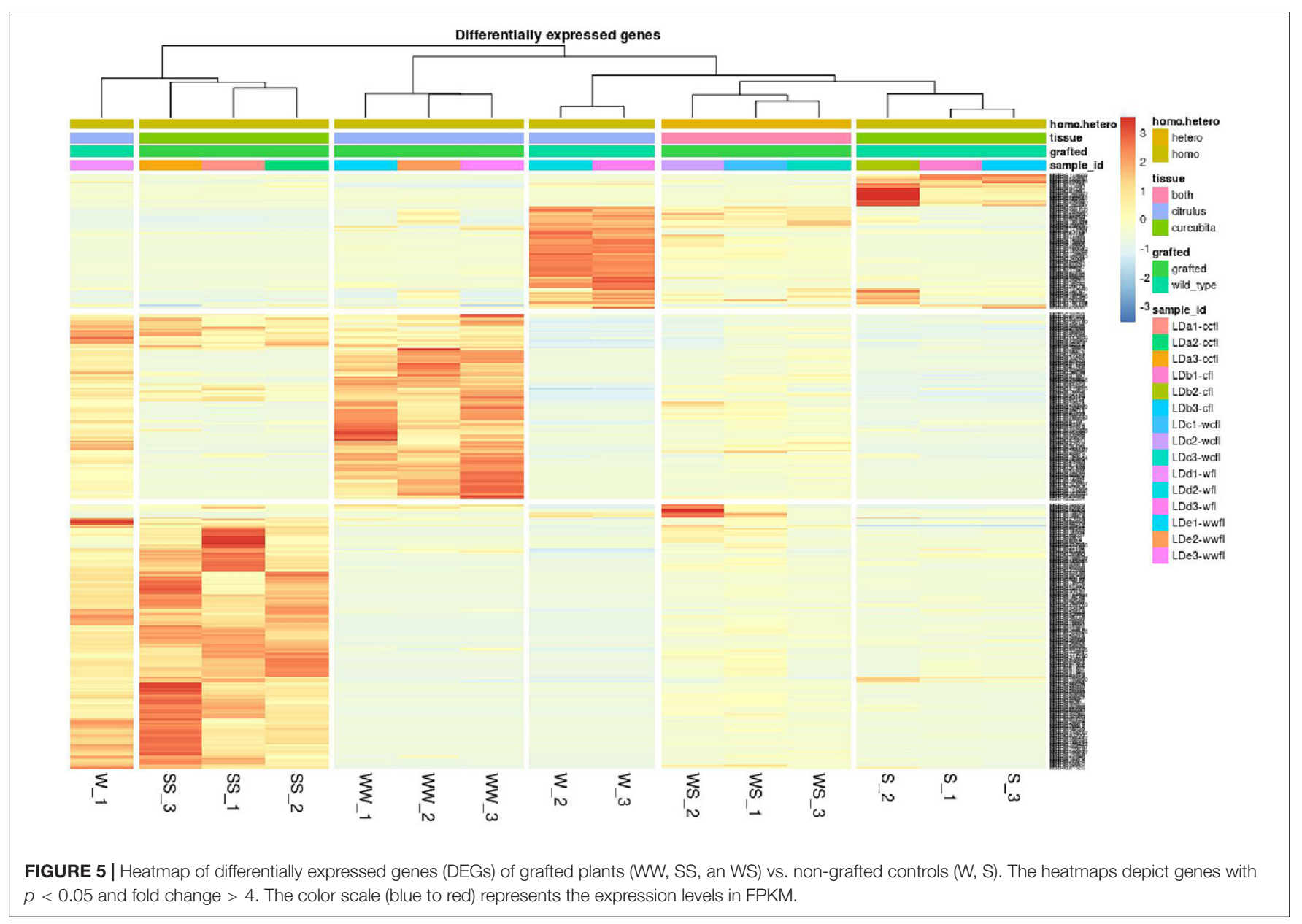

many dioxygenases that are related to the key steps in cell metabolism, affecting cell division and expansion (Fiorani et al., 2013). Therefore, the plants need AsA during the healing process after grafting. Wadano et al. (1999) reported that AsA increased sharply up to $8 \mathrm{~h}$ after grafting compared with control (nongrafted seedlings), while $30 \mathrm{~h}$ after grafting the content of the compound decreased to the level of control. Smirnoff (1996) showed that the AsA is required in the plants recovering from wounding. The plant signaling during grafting and wounding may share similar mechanisms, thus, a reasonable assumption is that the signal to increase AsA content may originate from the cell wall metabolism and cell expansion. In our study, two genes related to AsA transport, a nucleobase-AsA transporter 12like, and an AsA transporter, were DE between the WS and SS grafted seedlings. AsA transporter is reported to facilitate the AsA transport from the cytosol to the chloroplast (Miyaji et al., 2015), a necessary activity for the AsA intracellular distribution (Maurino et al., 2006).

The plant signal transduction pathways are interconnected and form a network that is finely regulated by the plant hormones (Liu et al., 2016). The auxins, gibberellins, CKs, abscisic acid, ethylene, and other plant hormones participate in the plant stress defense mechanisms (Han and Kahmann, 2019). In our study, several differentially regulated hormone-related genes were identified. These responses signify the role of different hormone pathways, such as auxin, gibberellic acid, ethylene, and CKs in the process of graft vascular connection. An auxin-regulated gene expression modulates plant growth and development. Similarly, the CK signaling promotes callus formation by manipulating the cell cycle proteins (Ikeuchi et al., 2017). The auxin and CK response are strongly enhanced in the pericycle and vascular cambium of the grafted Arabidopsis plants (Melnyk et al., 2015). The transcripts related to auxin transport (auxin efflux carrier component 5) and signaling (auxin-binding protein ABP19a-like) were upregulated in the SS/S comparison while an auxin transporter-like protein 1 was upregulated in WS compared with the WW grafted plants. The CKs regulate the vascular tissue adhesion-dependent upon the working of signaling receptors, such as AHK2, AHK3, and CKI1 His kinase (CYTOKININ INDEPENDENT 1) (Sharma and Zheng, 2019). Our results showed upregulation of the CK biosynthetic gene LOG5 possibly triggered in the plants during the process of wound healing, proposing the involvement of CK signaling in the graft development. The CKs are known as key regulators of plant growth and development, controlling proceedings, such as cell division, growth of shoot apical meristem, development of the vascular system, root growth, tissue patterning, and shoot organogenesis (Sharma and Zheng, 2019). Historically, the CKs 
TABLE 3 | The gene ontologies of mutually differentially expressed genes (DEGs) of homo-grafted watermelon (WW) and homo-grafted squash (SS).

\begin{tabular}{|c|c|c|c|c|c|}
\hline \multicolumn{6}{|c|}{ Gene ontologies of DEGs } \\
\hline GO:0006950 & Response to stress & GO:0016787 & Motor activity & GO:0005576 & Extracellular region \\
\hline GO:0010466 & Negative regulation of peptidase activity & GO:0016798 & $\begin{array}{l}\text { Hydrolase activity, acting on } \\
\text { glycosyl bonds }\end{array}$ & GO:0048046 & Apoplast \\
\hline GO:0010951 & Negative regulation of Endopeptidase activity & GO:0016491 & Oxidoreductase activity & GO:0016020 & Membrane \\
\hline GO:0008152 & Metabolic process & GO:0015238 & $\begin{array}{l}\text { Xenobiotic transmembrane } \\
\text { transporter activity }\end{array}$ & GO:0009507 & Chloroplast \\
\hline GO:0071555 & Cell wall organization & GO:0015297 & Antiporter activity & GO:0005886 & Plasma membrane \\
\hline GO:0055114 & Obsolete oxidation-reduction process & GO:0004601 & Peroxidase activity & & \\
\hline GO:0006855 & Drug transmembrane transport & GO:0020037 & Heme binding & & \\
\hline GO:0055085 & Transmembrane transport & GO:0046872 & Metal ion binding & & \\
\hline GO:0008643 & Carbohydrate transport & GO:0008289 & Lipid binding & & \\
\hline GO:0006090 & Pyruvate metabolic process & GO:0016740 & Transfer activity & & \\
\hline GO:0016310 & Phosphorylation & & & & \\
\hline GO:0006952 & Defense response & & & & \\
\hline GO:0009607 & Response to biotic stimulus & & & & \\
\hline GO:0006869 & Lipid transport & & & & \\
\hline
\end{tabular}

TABLE 4 | Genes were found to be differentially expressed (DE) among the comparisons. No common DEGs were found among the comparisons of WW, hetero-grafted watermelon onto squash (WS), and their controls.

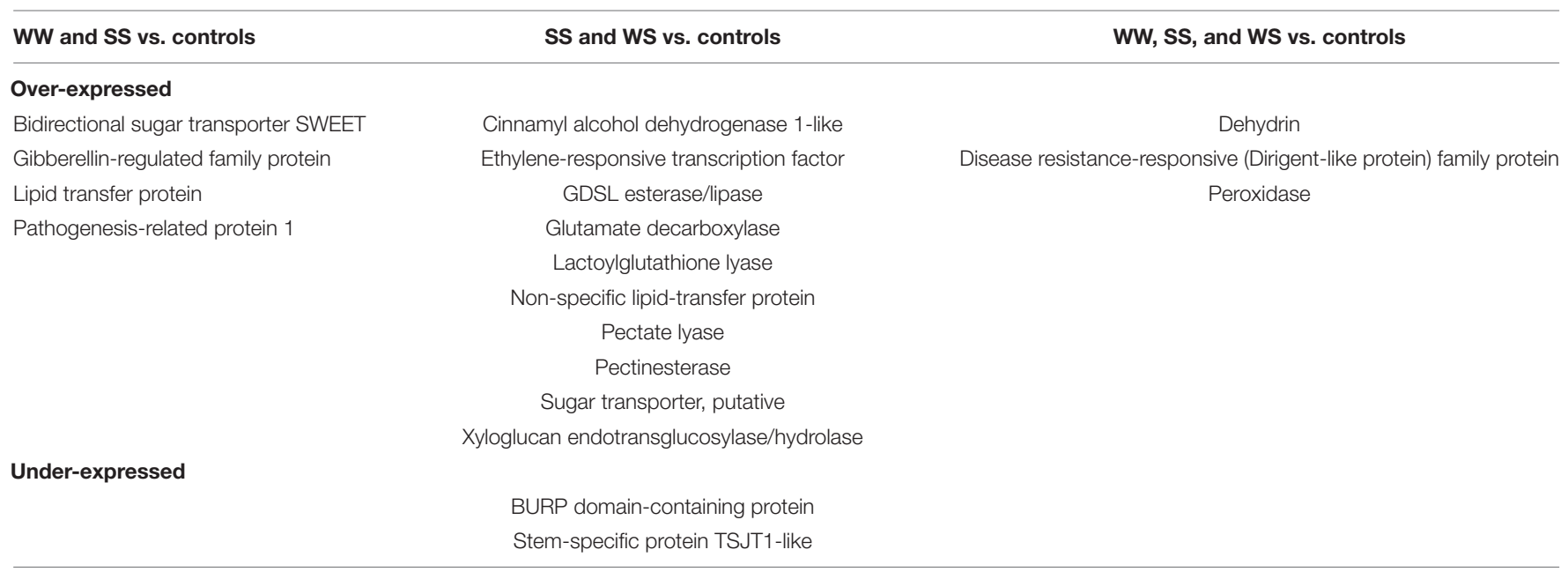

are regarded as root synthesized (Ghanem et al., 2011), although it has been revealed that the direct activation pathway via LOGs genes plays a pivotal role in regulating the CK activity during normal growth and development in Arabidopsis and rice (Kurakawa et al., 2007; Kuroha et al., 2009). Accordingly, our results demonstrated an increase of LOG5 transcript level in all the grafting combinations, which was higher in the homo-grafted SS followed by the hetero-grafted WS and homografted WW.

A gibberellin-regulated protein (GRP) gene was overexpressed in the WW and SS grafted seedlings compared with the control treatments. The expression of this gene is shown to be upregulated by the gibberellins which are important for plant growth and development (Muhammad et al., 2019), but the function of the GRP is not clear.

Ethylene is an important hormone that participates in various activities related to plant growth and development (Ju and Chang, 2015). In our study, the ethylene-responsive transcription factors (ERFs) ERF115, ERF114-like, ERF113like, and ERF110-like were over-expressed in WS and SS where the root system was removed, but not in WW where 


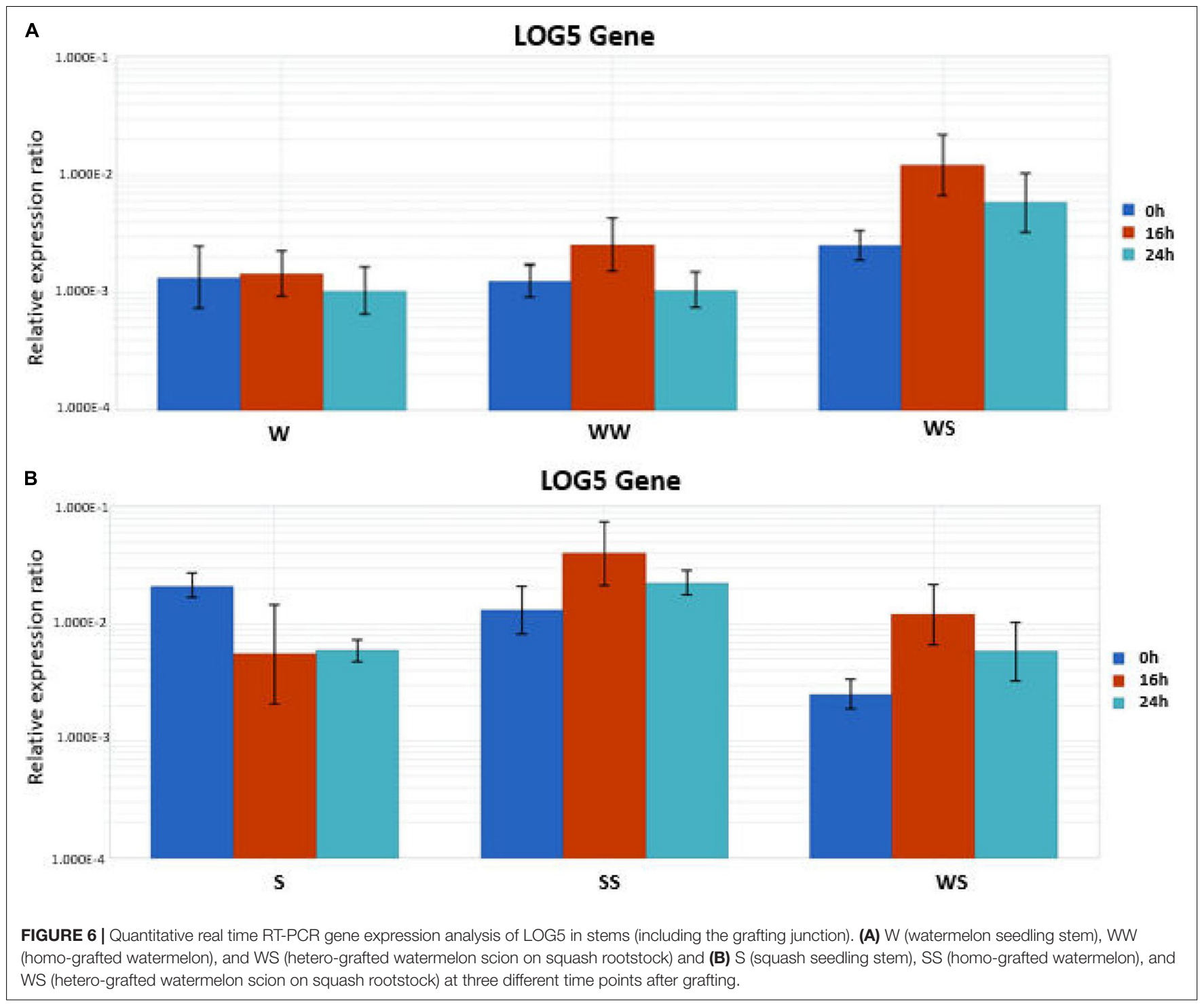

the root system was intact. The ERF family proteins are known for their ability to induce abiotic stress resistance in plants (Debbarma et al., 2019). Specifically, an ERF115 is demonstrated as a repressor of adventitious root initiation through the activation of $\mathrm{CK}$ and jasmonic acid signaling, the latter in NINJA-dependent and independent manners (Lakehal et al., 2020). An ERF114 is involved in the control of axillary bud outgrowth and cell proliferation, and activates the genes of the cell cycle and dormancy breaking, while it downregulates genes related to the cell wall-remodeling (Mehrnia et al., 2013). An ERF113 is a transcriptional activator participating in tolerance to the abiotic stress factors and plant development (Krishnaswamy et al., 2011). An ERF110 is assumed to act as a transcriptional activator through binding to the GCC-box pathogenesis-related promoter and is considered to participate in the stress-related gene expression patterns (Tao et al., 2018). Moreover, APETALA2/ERF (AP2/ERF) and xyloglucan endotransglucosylase/hydrolase were also upregulated in WS and SS compared with the non-grafted seedlings. AP2/ERF is the second largest family of TFs in the plants (Nakano et al., 2006). Quite similar to our findings, Spano et al. (2020) reported upregulated AP2/ERF and xyloglucan hydrolase in the self-grafted tomato plants. The abovementioned results of the transcriptional analysis of the grafted watermelon seedlings might provide an understanding of the interactions between the ERF genes and ethylene-dependent mechanisms during the healing process of watermelon grafted on interspecific squash.

Two genes, stem-specific TSJT1-like and BURB domaincontaining protein were under-expressed in SS and WS compared with the non-grafted seedlings. TSJT1 is suggested to act as a negative regulator of internode development in the castor plants, but the specific function of protein is not clear (Hu et al., 2016). Quite similarly with our findings, Zhang et al. (2018) reported that a stem-specific protein TSJT1-like (IPSR9) showed decreased expression patterns under salt and osmotic stress. The BURP 
domain-containing proteins impose variable effects related to the plant development and responses to abiotic stress factors, but knowledge about this protein family is rather scarce (Wang et al., 2015). However, it is known that they are responsive to the application of abscisic acid (Matus et al., 2014). Gautier et al. (2020) found that a BURP domain-containing protein was $\mathrm{DE}$ as a response to grapevine hetero-grafting in the two different rootstocks.

Recently, the SWEETs (Sugars Will Eventually be Exported Transporters) are identified as the cellular sugar transporters which enable sucrose efflux through the cell membranes, from the phloem parenchyma to the phloem apoplasm (Chen, 2014). Phloem and xylem, the two major vascular tissue types, are probably the most important tissues that quickly differentiate during the healing of grafted seedlings (Melnyk and Meyerowitz, 2015). Only recently, a total of 17 CsSWEET genes were identified in another cucurbit, cucumber ( $\mathrm{Hu}$ et al., 2017). The same authors reported that most of the CsSWEET genes were related to tissue development, while 18 ClaSWEET genes from watermelon and $18 \mathrm{CmSWEET}$ genes from melon were similar to the CsSWEET genes from cucumber. In our study, a SWEET16-like gene was overexpressed in WW and SS, compared with the nongrafted seedlings. SWEET16 is found to facilitate sugar efflux from the vacuoles while its regulation is critical for development under unfavorable conditions (Klemens et al., 2013). These results provide additional information about the regulation and activity of SWEET genes in response to grafting, a very stressful procedure for the plants.

In summary, our results suggest that at the $16 \mathrm{~h}$ time-point, the majority of the DEGs are implicated in wound healing, stress response, hormone biosynthesis, transport and signaling, and metabolite transport. The common genes that were found to be DE among the hetero- and homo-grafted seedlings suggest the presence of "core genes" that are responsible for healing in the grafting procedure per se, species independently. Furthermore, the common DEGs found among SS and WS give an insight into the genes that are probably regulated only in the rootstock. These findings broaden our understanding of the molecular events that pertain to the successful grafting in Cucurbitaceae and deliver new questions that necessitate further investigation-including a new experimental approach - to obtain a distinct profile of genes that regulate the connection of scion and rootstock in grafting.

\section{CONCLUSION}

In the present study, we performed a comprehensive transcriptomic analysis to examine the effect of grafting in the watermelon-squash scion-rootstock combinations. The control comparisons were performed to examine the effects of homografting. The comparison between SS and S exhibited the highest

\section{REFERENCES}

Bantis, F., Koukounaras, A., Siomos, A., Menexes, G., Dangitsis, C., and Kintzonidis, D. (2019). Assessing quantitative criteria for characterization of quality categories for grafted watermelon number of DE transcripts, while WW and W comparison followed. Squash had a more abrupt response to grafting compared with watermelon as shown by the differential gene expression. To examine the effects of grafting in the heterografted seedlings a de novo transcriptome, such as the genes from watermelon and squash, was assembled and used as a reference. Although the de novo transcriptome method offers a way to investigate the genes that were affected at the heterografted plants during the process of healing, the results should be used with caution regarding the levels of expression. Among the overexpressed genes, only one gene (LOG5) was common in three out of four comparisons involving WS, SS, and S and is related to the CK synthesis. Its expression levels were precisely quantified and the results concur with the transcriptomic data. The study is a description of the transcriptomic nature of homo- and heterografted early responses, while it provides a starting point for the elucidation of the molecular mechanisms and candidate genes for the functional analyses of hetero- and homo-graft systems in watermelon and generally in Cucurbitaceae.

\section{DATA AVAILABILITY STATEMENT}

The original contributions presented in the study are publicly available. This data can be found here: NCBI repository, accession number: PRJNA721571 (https://www.ncbi.nlm.nih.gov/bioproject/PRJNA721571).

\section{AUTHOR CONTRIBUTIONS}

FB, AP, AA, and AK: conceptualization, methodology, and data analysis. FB, GT, EM, and IT: experimental measurements. FB, GT, AP, and AK: writing-original draft preparation. AK: supervision and project administration. All authors: editing.

\section{FUNDING}

This research has been co-financed by the European Union and Greek national funds through the Operational Program Competitiveness, Entrepreneurship and Innovation, under the call RESEARCH-CREATE-INNOVATE (project code: T1EDK00960, LEDWAR.gr).

\section{ACKNOWLEDGMENTS}

We gratefully acknowledge Agris S.A., Greece for providing the plant material.

seedlings. Horticulturae 5:16. doi: 10.3390/horticulturae50 10016

Chen, L.-Q. (2014). SWEET sugar transporters for phloem transport and pathogen nutrition. New Phytol. 201, 1150-1155. doi: 10.1111/nph. 12445 
Cui, Q., Xie, L., Dong, C., Gao, L., and Shang, Q. (2021). Stage-specific events in tomato graft formation and the regulatory effects of auxin and cytokinin. Plant Sci. 304:110803. doi: 10.1016/j.plantsci.2020.110803

Davis, A. R., Perkins-Veazie, P., Sakata, Y., López-Galarza, S., Maroto, J. V., Lee, S.-G., et al. (2008). Cucurbit Grafting. Crit. Rev. Plant Sci. 27, 50-74. doi: $10.1080 / 07352680802053940$

Debbarma, J., Sarki, Y. N., Saikia, B., Boruah, H. P. D., Singha, D. L., and Chikkaputtaiah, C. (2019). Ethylene Response Factor (ERF) Family Proteins in Abiotic Stresses and CRISPR-Cas9 Genome Editing of ERFs for Multiple Abiotic Stress Tolerance in Crop Plants: a Review. Mol. Biotechnol. 61, 153-172. doi: 10.1007/s12033-018-0144-X

Erhirhie, E. O., and Ekene, N. E. (2013). Medicinal values on Citrullus lanatus (watermelon): pharmacological review. Int. J. Res. Pharm. Biomed. Sci. 4, 1305-1312.

Fallik, E., Alkalai-Tuvia, S., Chalupowicz, D., Popovsky-Sarid, S., and ZaaroorPresman, M. (2019). Relationships between Rootstock-Scion Combinations and Growing Regions on Watermelon Fruit Quality. Agronomy 9:536. doi: 10.3390/ agronomy 9090536

Fernandez-Garcia, N., Carvajal, M., and Olmos, E. (2004). Graft union formation in tomato plants: peroxidase and catalase involvement. Ann. Bot. 93, 53-60. doi: $10.1093 / \mathrm{aob} / \mathrm{mch} 014$

Fiorani, M., Azzolini, C., Cerioni, L., Guidarelli, A., and Cantoni, O. (2013). Superoxide dictates the mode of U937 cell ascorbic acid uptake and prevents the enhancing effects of the vitamin to otherwise nontoxic levels of reactive oxygen/nitrogen species. J. Nutr. Biochem. 24, 467-474. doi: 10.1016/j.jnutbio. 2012.01.009

Food and Agriculture Organization of the United Nations (2012). FAOSTAT Database. Rome, Italy: FAO.

Fotopoulos, V., and Kanellis, A. K. (2013). Altered apoplastic ascorbate redox state in tobacco plants via ascorbate oxidase overexpression results in delayed darkinduced senescence in detached leaves. Plant Physiol. Biochem. 73, 154-160. doi: 10.1016/j.plaphy.2013.09.002

Fuentes, I., Stegemann, S., Golczyk, H., Karcher, D., and Bock, R. (2014). Horizontal genome transfer as an asexual path to the formation of new species. Nature 511, 232-235. doi: 10.1038/nature13291

Garcia-Lozano, M., Dutta, S. K., Natarajan, P., Tomason, Y. R., Lopez, C., Katam, R., et al. (2020). Transcriptome changes in reciprocal grafts involving watermelon and bottle gourd reveal molecular mechanisms involved in increase of the fruit size, rind toughness and soluble solids. Plant Mol. Biol. 102, 213-223. doi: 10.1007/s11103-019-00942-7

Gaut, B. S., Miller, A. J., and Seymour, D. K. (2019). Living with Two Genomes: grafting and Its Implications for Plant Genome-to-Genome Interactions, Phenotypic Variation, and Evolution. Annu. Rev. Genet. 53, 195-215. doi: 10.1146/annurev-genet-112618-043545

Gautier, A. T., Cochetel, N., Merlin, I., Hevin, C., Lauvergeat, V., Vivin, P., et al. (2020). Scion genotypes exert long distance control over rootstock transcriptome responses to low phosphate in grafted grapevine. BMC Plant Biol. 20:367. doi: 10.1186/s12870-020-02578-y

Ghanem, M. E., Hichri, I., Smigocki, A. C., Albacete, A., Fauconnier, M. L., Diatloff, E., et al. (2011). Root-targeted biotechnology to mediate hormonal signalling and improve crop stress tolerance. Plant Cell Rep. 30, 807-823. doi: 10.1007/ s00299-011-1005-2

Goldschmidt, E. E. (2014). Plant grafting: new mechanisms, evolutionary implications. Front. Plant Sci. 5:727. doi: 10.3389/fpls.2014.00727

Han, X., and Kahmann, R. (2019). Manipulation of Phytohormone Pathways by Effectors of Filamentous Plant Pathogens. Front. Plant Sci. 10:822. doi: 10.3389/ fpls.2019.00822

Hu, L.-P., Zhang, F., Song, S.-H., Tang, X.-W., Xu, H., Liu, G.-M., et al. (2017). Genome-wide identification, characterization, and expression analysis of the SWEET gene family in cucumber. J. Integr. Agric. 16, 1486-1501. doi: 10.1016/ S2095-3119(16)61501-0

Hu, W., Chen, L., Qiu, X., Lu, H., Wei, J., Bai, Y., et al. (2016). Morphological, Physiological and Proteomic Analyses Provide Insights into the Improvement of Castor Bean Productivity of a Dwarf Variety in Comparing with a High-Stalk Variety. Front. Plant Sci. 7:1473. doi: 10.3389/fpls.2016. 01473

Ikeuchi, M., Iwase, A., Rymen, B., Lambolez, A., Kojima, M., Takebayashi, Y., et al. (2017). Wounding triggers callus formation via dynamic hormonal and transcriptional changes. Plant Physiol. 175, 1158-1174. doi: 10.1104/pp.17. 01035

Iwase, A., Mitsuda, N., Koyama, T., Hiratsu, K., Kojima, M., Arai, T., et al. (2011). The AP2/ERF transcription factor WIND1 controls cell dedifferentiation in arabidopsis. Curr. Biol. 21, 508-514. doi: 10.1016/j.cub.2011. 02.020

Ju, C., and Chang, C. (2015). Mechanistic insights in ethylene perception and signal transduction. Plant Physiol. 169, 85-95. doi: 10.1104/pp.15.00845

Kim, D., Pertea, M., Kim, D., Pertea, G. M., Leek, J. T., and Salzberg, S. L. (2016). Transcript-level expression analysis of RNA- seq experiments with HISAT, StringTie and Transcript-level expression analysis of RNA-seq experiments with HISAT, StringTie and Ballgown. Nat. Protoc. 11, 1650-1667. doi: 10.1038/ nprot.2016.095

Klemens, P. A. W., Patzke, K., Deitmer, J., Spinner, L., Le Hir, R., Bellini, C., et al. (2013). Overexpression of the Vacuolar Sugar Carrier AtSWEET16 Modifies Germination, Growth, and Stress Tolerance in Arabidopsis. Plant Physiol. 163, 1338-1352. doi: 10.1104/pp.113.224972

Kong, Q., Yuan, J., Gao, L., Zhao, S., Jiang, W., Huang, Y., et al. (2014). Identification of suitable reference genes for gene expression normalization in qRT-PCR analysis in watermelon. PLoS One 9:e90612. doi: 10.1371/journal. pone.0090612

Krishnaswamy, S., Verma, S., Rahman, M. H., and Kav, N. N. (2011). Functional characterization of four APETALA2-family genes (RAP2.6, RAP2.6L, DREB19 and DREB26) in Arabidopsis. Plant Mol. Biol. 75, 107-127. doi: 10.1007/ s11103-010-9711-7

Kurakawa, T., Ueda, N., Maekawa, M., Kobayashi, K., Kojima, M., Nagato, Y., et al. (2007). Direct control of shoot meristem activity by a cytokinin-activating enzyme. Nature 445, 652-655. doi: 10.1038/nature05504

Kuroha, T., Tokunaga, H., Kojima, M., Ueda, N., Ishida, T., Nagawa, S., et al. (2009). Functional analyses of LONELY GUY cytokinin-activating enzymes reveal the importance of the direct activation pathway in Arabidopsis. Plant Cell 21, 3152-3169. doi: 10.1105/tpc.109.068676

Kyriacou, M. C., and Soteriou, G. (2015). Quality and postharvest performance of watermelon fruit in response to grafting on interspecific cucurbit rootstocks. J. Food Qual. 38, 21-29. doi: 10.1111/jfq.12124

Lakehal, A., Dob, A., Rahneshan, Z., Novák, O., Escamez, A., Alallaq, A., et al. (2020). ETHYLENE RESPONSE FACTOR 115 integrates jasmonate and cytokinin signaling machineries to repress adventitious rooting in Arabidopsis. New Phytol. 228, 1611-1626. doi: 10.1111/nph.16794

Lee, J. M., Kubota, C., Tsao, S. J., Bie, Z., Hoyos Echevarria, P., Morra, L., et al. (2010). Current status of vegetable grafting: diffusion, grafting techniques, automation. Sci. Hortic. 127, 93-105. doi: 10.1016/j.scienta.2010.08.003

Liu, N., Yang, J., Fu, X., Zhang, L., Tang, K., Guy, K. M., et al. (2016). Genomewide identification and comparative analysis of grafting-responsive mRNA in watermelon grafted onto bottle gourd and squash rootstocks by highthroughput sequencing. Mol. Genet. Genomics 291, 621-633. doi: 10.1007/ s00438-015-1132-5

Louws, F. J., Rivard, C. L., and Kubota, C. (2010). Grafting fruiting vegetables to manage soilborne pathogens, foliar pathogens, arthropods and weeds. Sci. Hortic. 127, 127-146. doi: 10.1016/j.scienta.2010.09.023

Matus, J. T., Aquea, F., Espinoza, C., Vega, A., Cavallini, E., Santo, S. D., et al. (2014). Inspection of the grapevine BURP superfamily highlights an expansion of RD22 genes with distinctive expression features in berry development and ABA-mediated stress responses. PLoS One 9:e110372. doi: 10.1371/journal. pone.0110372

Maurino, V. G., Grube, E., Zielinski, J., Schild, A., Fischer, K., and Flügge, U.-I. (2006). Identification and Expression Analysis of Twelve Members of the Nucleobase-Ascorbate Transporter (NAT) Gene Family in Arabidopsis thaliana. Plant Cell Physiol. 47, 1381-1393. doi: 10.1093/pcp/pcl011

Mehrnia, M., Balazadeh, S., Zanor, M. I., and Mueller-Roeber, B. (2013). EBE, an AP2/ERF transcription factor highly expressed in proliferating cells, affects shoot architecture in Arabidopsis. Plant Physiol. 162, 842-857. doi: 10.1104/pp. 113.214049

Melnyk, C. W., and Meyerowitz, E. M. (2015). Plant grafting. Cur. Biol. 25, 183-188. doi: 10.1016/j.cub.2015.01.029

Melnyk, C. W., Schuster, C., Leyser, O., and Meyerowitz, E. M. (2015). A developmental framework for graft formation and vascular reconnection in arabidopsis thaliana. Curr. Biol. 25, 1306-1318. doi: 10.1016/j.cub.2015.03.032 
Mittler, R. (2002). Oxidative stress, antioxidants and stress tolerance. Trends Plant Sci. 7, 405-410. doi: 10.1016/S1360-1385(02)02312-9

Miyaji, T., Kuromori, T., Takeuchi, Y., Yamaji, N., Yokosho, K., Shimazawa, A., et al. (2015). AtPHT4;4 is a chloroplast-localized ascorbate transporter in Arabidopsis. Nat. Commun. 6:5928. doi: 10.1038/ncomms6928

Muhammad, I., Li, W.-Q., Jing, X.-Q., Zhou, M.-R., Shalmani, A., Ali, M., et al. (2019). A systematic in silico prediction of gibberellic acid stimulated GASA family members: a novel small peptide contributes to floral architecture and transcriptomic changes induced by external stimuli in rice. J. Plant Physiol. 234-235, 117-132. doi: 10.1016/j.jplph.2019.02.005

Nakano, T., Suzuki, K., Fujimura, T., and Shinshi, H. (2006). Genome-wide analysis of the ERF gene family in rice and Arabidopsis. Plant Physiol. 140, 411-432. doi: 10.1104/pp.105.073783

Nanda, A. K., and Melnyk, C. W. (2018). The role of plant hormones during grafting. J. Plant Res. 131, 49-58. doi: 10.1007/s10265-017-0994-5

Pandey, V. P., Awasthi, M., Singh, S., Tiwari, S., and Dwived, U. N. (2017). A comprehensive review on function and application of plant peroxidases. Biochem. Anal. Biochem. 6:1. doi: 10.4172/2161-1009.1000308

Savvas, D., Colla, G., Rouphael, Y., and Schwarz, D. (2010). Amelioration of heavy metal and nutrient stress in fruit vegetables by grafting. Sci. Hortic. 127, 156-161. doi: 10.1016/j.scienta.2010.09.011

Schwarz, D., Rouphael, Y., Colla, G., and Venema, J. H. (2010). Grafting as a tool to improve tolerance of vegetables to abiotic stresses: thermal stress, water stress and organic pollutants. Sci. Hortic. 127, 162-171. doi: 10.1016/j.scienta.2010. 09.016

Sharma, A., and Zheng, B. (2019). Molecular responses during plant grafting and its regulation by auxins, cytokinins, and gibberellins. Biomolecules 9:397. doi: 10.3390/biom 9090397

Smirnoff, N. (1996). The function and metabolism of ascorbic acid in plants. Ann. Bot. 78, 661-669. doi: 10.1006/anbo.1996.0175

Soteriou, G. A., Kyriacou, M. C., Siomos, A. S., and Gerasopoulos, D. (2014). Evolution of watermelon fruit physicochemical and phytochemical composition during ripening as affected by grafting. Food Chem. 165, 282-289. doi: 10.1016/j.foodchem.2014.04.120

Spano, R., Ferrara, M., Gallitelli, D., and Mascia, T. (2020). The Role of Grafting in the Resistance of Tomato to Viruses. Plants 9:1042. doi: 10.3390/plants9081042

Stegemann, S., and Bock, R. (2009). Exchange of Genetic Material Between Cells in Plant Tissue Grafts. Science 324, 649-651. doi: 10.1126/science.1170397

Stegemann, S., Keuthe, M., Greiner, S., and Bock, R. (2012). Horizontal transfer of chloroplast genomes between plant species. Proc. Natl. Acad. Sci. U. S. A. 109, 2434-2438. doi: 10.1073/pnas.1114076109

Suza, W. P., Avila, C. A., Carruthers, K., Kulkarni, S., Goggin, F. L., and Lorence, A. (2010). Exploring the impact of wounding and jasmonates on ascorbate metabolism. Plant Physiol. Biochem. 48, 337-350. doi: 10.1016/j.plaphy.2010. 02.004

Taller, J., Yagishita, N., and Hirata, Y. (1999). Graft-induced variants as a source of novel characteristics in the breeding of pepper (Capsicum annuum L.). Euphytica 108, 73-78. doi: 10.1023/A:1003681913996

Tao, Q., Niu, H., Wang, Z., Zhang, W., Wang, H., Wang, S., et al. (2018). Ethylene responsive factor ERF110 mediates ethylene-regulated transcription of a sex determination-related orthologous gene in two Cucumis species. J. Exp. Bot. 69, 2953-2965. doi: 10.1093/jxb/ery128

Tsaballa, A., Athanasiadis, C., Pasentsis, K., Ganopoulos, I., Nianiou-Obeidat, I., and Tsaftaris, A. (2013). Molecular studies of inheritable grafting induced changes in pepper (Capsicum annuum) fruit shape. Sci. Hortic. 149, 2-8. doi: 10.1016/j.scienta.2012.06.018

Wadano, A., Azeta, M., Itotani, S.-I., Kanda, A., Iwaki, T., Taira, T., et al. (1999). Change of Ascorbic Acid Level after Grafting of Tomato Seedlings. Z. Naturforsch. 54, 830-833. doi: 10.1515/znc-1999-91032

Wang, H., Zhou, P., Zhu, W., and Wang, F. (2019). De novo Comparative Transcriptome Analysis of Genes Differentially Expressed in the Scion of Homografted and Heterografted Tomato Seedlings. Sci. Rep. 9:20240. doi: 10.1038/s41598-019-56563-Z

Wang, L., Wu, N., Zhu, Y., Song, W., Zhao, X., Li, Y., et al. (2015). The divergence and positive selection of the plant-specific BURP-containing protein family. Ecol. Evol. 5, 5394-5412. doi: 10.1002/ece3.1792

Xie, L., Dong, C., and Shang, Q. (2019). Gene co-expression network analysis reveals pathways associated with graft healing by asymmetric profiling in tomato. BMC Plant Biol. 19:373. doi: 10.1186/s12870-0191976-7

Yeoman, M. M., and Brown, R. (1976). Implications of the Formation of the Graft Union for Organisation in the Intact Plant. Ann. Bot. 40, 1265-1276. doi: 10.1093/oxfordjournals.aob.a085247

Yin, H., Yan, B., Sun, J., Jia, P., Zhang, Z., Yan, X., et al. (2012). Graft-union development: a delicate process that involves cell-cell communication between scion and stock for local auxin accumulation. J. Exp. Bot. 63, 4219-4232. doi: $10.1093 /$ jxb/ers 109

Zhang, M., Zhang, H., Zheng, J.-X., Mo, H., Xia, K.-F., and Jian, S.-G. (2018). Functional Identification of Salt-Stress-Related Genes Using the FOX Hunting System from Ipomoea pescaprae. Int. J. Mol. Sci. 19:3446. doi: 10.3390/ ijms19113446

Conflict of Interest: The authors declare that the research was conducted in the absence of any commercial or financial relationships that could be construed as a potential conflict of interest.

Publisher's Note: All claims expressed in this article are solely those of the authors and do not necessarily represent those of their affiliated organizations, or those of the publisher, the editors and the reviewers. Any product that may be evaluated in this article, or claim that may be made by its manufacturer, is not guaranteed or endorsed by the publisher.

Copyright (c) 2021 Bantis, Tsiolas, Mouchtaropoulou, Tsompanoglou, Polidoros, Argiriou and Koukounaras. This is an open-access article distributed under the terms of the Creative Commons Attribution License (CC BY). The use, distribution or reproduction in other forums is permitted, provided the original author(s) and the copyright owner(s) are credited and that the original publication in this journal is cited, in accordance with accepted academic practice. No use, distribution or reproduction is permitted which does not comply with these terms. 